Revista ComSertões

\title{
A Identidade Cultural do Homem Ribeirinho através da Análise dos seus Mitos e Lendas
}

Cynara Adriana Sento-Sé Magalhães Cordeiro Celestino Alves ${ }^{1}$

\section{Resumo}

Esse artigo discute os mecanismos psicanalíticos que subjazem no processo de construção da identidade cultural da comunidade ribeirinha que habita a Ilha Canabrava, quarta maior ilha do médio São Francisco, através da análise do universo lendário habitado pelo Compadre D’Água, entidade que domina as águas do Rio São Francisco. Navegando pelas teorias freudianas e lacanianas, teorias essas que abordam a constituição do sujeito, e, por extensão a construção da identidade cultural de um povo, procuro demonstrar como a lenda do Compadre D’Água contribui para a formação da identidade cultural desta comunidade.

Palavras-chave: Identidade; Identificação; Cultura; Psicanálise.

\section{Resumen}

Este artículo discute los mecanismos psicoanalíticos que subyacen a la construcción de la identidad cultural en la comunidad ribereña que habita en el proceso Isla Canabrava, la cuarta isla más grande en el río San Francisco, a través del análisis del universo mítico habitado por entidad Compadre D'Água que domina las aguas río São Francisco. Navegando por las teorías freudianas y lacanianos, estas teorías que abordan la constitución del sujeto, y por extensión el de la construcción de la identidad cultural de un pueblo, que tratan de demostrar cómo la leyenda del Compadre de agua contribuye a la formación de la identidad cultural de esta comunidad.

Palabras clave: Identidad; identificación; Cultura; Psicoanálisis.

\begin{abstract}
This article reveals the psychoanalytic mechanisms that lie in the process of construction of the cultural identity of the riverside community that lives in the Ilha Canabrava, through the legendary universe lived by the Compadre D'Água, entity that dominates the waters of the Rio Saint Francisco. Sailing for the Freudian theories and lacanianas, that board the constitution of the subject and for extension the construction of the cultural identity of a people, I try to demonstrate like the legend of the Compadre D'Água contributes to the formation of the cultural identity of this community.
\end{abstract}

Keywords: Identity; Identification; Culture; Psychoanalysis.

1 Psicóloga, psicopedagoga, professora especialista da Universidade do Estado da Bahia - UNEB, DCHT/Campus XVII, Bom Jesus da Lapa - Bahia. cynarasentose@gmail.com 


\section{Revista ComSertões}

\section{INTRODUÇÃO}

Muito difundida entre a população ribeirinha do São Francisco, a lenda do Nego D’Água ou Compadre D’água, ou ainda conhecido como Caboclo D’água tem origem obscura. Semelhante a outras lendas de personagens ligados aos ambientes naturais (CASCUDO, 1972), o Nego D’Água habita apenas rios, e assusta pescadores, partindo anzóis de pesca, furando redes ou dando sustos em pessoas embarcadas. Meio homem, meio anfíbio, as pessoas o descrevem como um homem negro, atarracado, com nadadeiras, cor de pó e pele coberta de escamas.

Muitas pessoas, dentre a população ribeirinha do São Francisco, sob o impulso da crença nas lendas locais, afirmam que viram o Nego D’Água. Alguns, inclusive, tomam medidas preventivas contra a sua ação, colocando, por exemplo, cacos de vidro em ribanceiras para assustá-los. Outros adotam tática diversa, a de conquistar a simpatia do Nego D’água, atirando fumo ou beiju no rio.

A lenda é utilizada pelas mães para controlar o desejo dos filhos de se aproximar do rio e, por conseguinte, de seus perigos. Amedrontados com a possibilidade de encontrar o Nego D’água - muitos acreditam que haja apenas um Nego D’água em todo o rio, outros acreditam serem muitos, as crianças evitam se aproximar da água (CASCUDO,1972).

A existência de crenças e lendas no São Francisco, como a do Nego d'Água, está ligada ao habitat e às condições sociais e culturais da região. Desta maneira, estas estórias estão, em sua maioria, relacionadas principalmente com a água, a prática da pesca e com a fauna e a flora específicas deste habitat, pois nada do que ocorre em um conto popular, uma lenda, ou um mito, é gratuito ou supérfluo. Contra o que possa parecer, tudo nele tem um sentido, mais ou menos oculto, mais ou menos evoluído a partir de antigas crenças, ritos, costumes, através dos quais a humanidade forjou a si mesma, imprimindo na tradição oral o testemunho do caminho percorrido.

A cultura popular e o folclore, de uma maneira geral, representam aspectos culturais próprios da região na qual são construídos e difundidos, ou seja, eles têm vida própria (CASCUDO, 1972). São, por assim dizer, espelhos da própria identidade cultural da população e permitem compreender aspectos de sua concepção de mundo.

A construção e difusão de uma lenda, como a do Nego D'água, refletem as diferentes formas como o indivíduo recebe, interpreta, transforma e repassa a cultura em que está 


\section{Revista ComSertões}

inserido. Compreender as maneiras pelas quais esta lenda está difundida socialmente em um grupo determinado implica não somente conhecer o aspecto cultural da comunidade ribeirinha do São Francisco, mas, especialmente, interpretar as suas relações com a construção da identidade cultural na constituição do sujeito.

Como delimitação do campo da pesquisa, procurei analisar as várias formas que a lenda do Nego D’água se manifesta, particularmente na Ilha da Canabrava, quarta maior ilha do médio São Francisco, localizada no município de Bom Jesus da Lapa - Bahia, tendo como tema a construção da identidade cultural do homem ribeirinho através da análise dos seus mitos e lendas. Natural do Vale do São Francisco, cresci ouvindo a subversão da gramática, construída nas conversas e nos "causos" contados na beira das calçadas, sob á luz dos candeeiros, após um dia de trabalho. Nesses encontros que marcaram minha infância ocorreu transmissão de idéias, de valores, troca de experiências, de desejos, de sentimentos, de conhecimentos: era a manifestação da cultura espontânea, emanada a partir do encontro entre pessoas do campo e pessoas da cidade. Esses encontros foram determinantes para tornar-me o que sou como pessoa e como profissional. Nesse contexto, o presente trabalho se fundamentou em alguns pontos:

- Na comunidade da Ilha da Canabrava, não totalmente absorvida pelo sistema econômico capitalista, o homem ribeirinho ainda recorre aos mitos e lendas e histórias em geral para compreender o universo no qual está inserido?

- A Identidade Cultural do Homem Ribeirinho através da Análise de seus Mitos e Lendas,

mais especificamente, o Compadre D’Água, demonstrando como essa lenda contribui para a construção da subjetividade humana na comunidade da ilha da Canabrava.

- O lendário Compadre D’Água atuando como organizador social, estabelecendo as leis necessárias para o bom funcionamento das pessoas organizadas nessa comunidade.

- A relação do Homem com a Lei, e o papel desta interação na construção da identidade cultural dessa comunidade.

- A conexão entre o inconsciente e a gênese da lenda, através dos recursos oferecidos pela Psicanálise, tanto no seu viés freudiano quanto no viés Lacaniano.

Essa pesquisa foi realizada utilizando a metodologia qualitativa como recurso mais apropriado nas Ciências Humanas, para observar e analisar como a lenda do Compadre 


\section{Revista ComSertões}

D’água adquire diversas formas e contribui para a construção da identidade cultural dos moradores da comunidade ribeirinha da ilha da Canabrava, pesquisa essa caracterizada pelo caráter dialógico, de observação, analise e interpretação da realidade. Na execução desse estudo foi envolvida pesquisa bibliográfica, onde foi analisada fonte teórica inserida em livros de compreensão sobre o tema proposto para o trabalho, coleta de depoimentos entre os moradores da comunidade ribeirinha para identificar, observação na dinâmica da comunidade e analise de todas essas informações obtidas.

\section{O Lendário Rio São Francisco e a Ilha da Canabrava}

O Rio São Francisco é considerado o rio mais extenso do Brasil, uma vez que os 2.897 km entre sua nascente e sua foz estão totalmente dentro do território brasileiro, à diferença do Rio Amazonas, que é maior, mas tem parte de seu curso em território peruano. A ilha da Canabrava está localizada no município de Bom Jesus da Lapa, dentro do Rio São Francisco, orientada no sentido SullNorte, mesma direção do fluxo normal do rio, que nasce na serra da Canastra, no Sul de Minas Gerais, e toma a direção norte até a cidade de Remanso, no Estado da Bahia, onde tende levemente para o Leste, até atingir o Oceano Atlântico (PIERSON, 1972).

Bom Jesus da Lapa é uma cidade comercial e centro de serviços do estado da Bahia, situada às margens do rio São Francisco. Sua população é de 70 mil habitantes e caracterizase como importante centro de romarias religiosas do sertão baiano. Controla economicamente um conjunto de cinco municípios e subordina-se a duas cidades de maior importância, Barreiras e Feira de Santana. É considerado o porto fluvial de maior atividade da porção sul do vale do São Francisco baiano, sendo também um entroncamento rodoviário importante.

Paralelamente, sua função religiosa é considerada a mais poderosa do sertão do São Francisco, atraindo milhares de romeiros por ocasião dos festejos do padroeiro de Bom Jesus da Lapa. A ilha se estende em uma distância de $5.800 \mathrm{~m}$, distância esta que separa as duas extremidades Sul/Norte, e se expande na direção Leste/Oeste, com uma largura máxima de 1.200 m e uma largura média de 460 m, o correspondente a uma área total de 266.00 hectares. Área que nos anos setenta era extremamente fértil como todas as demais áreas ribeirinhas, pois até então o Rio são Francisco merecidamente recebia o nome de Nilo Brasileiro, dada a grande fertilidade das suas águas. Hoje, se nota uma ilha com um solo empobrecido, 


\section{Revista ComSertões}

ressecado, e até impróprio para a agricultura em algumas áreas. Razão pela qual grande parte dos moradores que lá hoje vivem, optou pela pecuária, com a criação de caprinos, bovinos, suínos. A ilha tem uma altitude média de $421 \mathrm{~m}$ acima do nível do mar. Na sua história recente, sabe-se que foi totalmente inundada nas cheias de 1949, 1979 e 1980.

\section{2. $O$ inconsciente na cultura}

Em O Ego e o Id (1923), Freud aborda a construção do 'Eu' sob dois pontos de vista: o primeiro como fisiologista e naturalista, explicando seu nascimento de forma evolutiva, como uma parte distinta do id, através de seu contato com a realidade externa, que o estimula por ser excitante: ele seria um mediador entre o contexto exterior e o id. $\mathrm{O}$ segundo, psicológico e estrutural, vê a gênese do 'eu' como um longo processo que, partindo da imagem corporal e do corpo vivenciado, em um campo de relações interpessoais, organiza aos poucos introjeções e diversos processos de simbolização integradora, diante de sucessivos mecanismos de identificações, $o$ "eu é um conjunto coerente de pré julgamentos, que, de um ponto de vista metahistórico são temáticas ou significados recorrentes” (FREUD, 1923. p. 55). O superego cuida da instância crítica do pensamento. Ele é a expressão das proibições, leis e normas familiares e sociais em geral, exerce assim seu domínio sobre o "eu”, punindo-o com um sentimento de culpa e de desaprovação quando ele tenta violar estas regras, agora interiorizadas em virtude das implicações do Complexo de Édipo.

Em 1924, em A dissolução do complexo de Édipo, Freud coloca como fator principal de sua origem a identificação com a família, principalmente com a figura do pai, não apenas enquanto indivíduo, mas especialmente como símbolo cultural. Este processo parece produzir no 'eu' nascente, mais tarde, uma "diferenciação" que se organiza como instância própria, com uma dupla aparência - como crítica e proibidora, por um lado, e como Ideal do "eu", modelo a se imitar, por outro.

Ainda de acordo com Freud (1914), o narcisismo em sua face primordial está conectado a esse instante em que são estabelecidos no sujeito, através do olhar alheio, esses atributos que o definem para os outros e para si mesmo. A criança passa então a ser nutrida por uma imagem ao mesmo tempo absorvida e perfeita, mas também poderá, a partir daí, definir-se, identificar-se, reconhecer-se. Esse reflexo é o que Freud define como "eu ideal". A partir daí o sujeito desenvolve uma relação de amor consigo mesmo que daí para frente se 


\section{Revista ComSertões}

transformará numa busca, a demanda de se tornar objeto do amor do outro. A evolução do 'Eu' do indivíduo só ocorre quando ele se distancia deste narcisismo primário, em um movimento de deslocamento da libido para outro objeto que não o "eu ideal".

Como abordado aqui, uma comunidade que praticamente se encontra na sua infância, pode-se arriscar afirmar que sua libido se desloca justamente através do significante, como defende Lacan, através do processo metonímico, com a entrada do grupo na esfera do simbólico, ou seja, no universo do lendário. Portanto, é possível pensar que a lenda, neste caso, propicia aos ribeirinhos transcender a etapa do narcisismo primário e de todas as suas implicações incestuosas.

Para melhor compreender esta transição, é necessário analisar o ponto de vista lacaniano sobre a construção do 'Eu' e sua concepção a respeito do Narcisismo. Em seus Escritos (1949), Lacan postula que em um primeiro momento ocorre o movimento pendular, através do qual a criança constrói sua imagem por meio do reflexo que lhe é devolvido pelo espelho, revelando-lhe um 'eu' que ele estranha, desconhece, mas que se apresenta como ele mesmo.

Assim, dentro do sujeito se estabelece um estranhamento de si mesmo, um outro indesejável e invasor, o que provoca uma certa tensão com relação a esta entidade que, através dos desejos que revela, impõe ao sujeito seus objetos, enquanto por outro lado os oculta dele, por meio do mesmo movimento pelo qual ele o esconde de si.

O olhar do outro, especialmente da mãe, restitui a imagem do indivíduo a si mesmo, pois é a representação materna sua única fonte imagética nesta etapa, e é para ela que a criança se volta à procura do consentimento do Outro simbólico. Assim a criança elabora seu narcisismo primário, construindo o reflexo de um eu-ideal constituído pelos significantes inscritos pela mãe sobre seu corpo.

Pode-se dizer então que, para Lacan (1953), a relação simbólica define a posição do sujeito. A palavra define o maior ou menor grau de perfeição, de completitude, de aproximação do imaginário. Assim, repito, a palavra torna possível à entrada na ordem simbólica, a qual nos leva à idéia do significante lingüístico. Este não é só significante de um desejo, o qual está ligado ao eu-ideal e ao desejo da mãe - falo imaginário -, também é significante de uma falta, presença de uma ausência, substituindo o que não se encontra, aparecendo em substituição de outra coisa, "a linguagem teria para o homem a mesma função de uma ponte a ligar dois pontos separados por um abismo" (CASTRO, 1996, p. 51): Haveria 


\section{Revista ComSertões}

uma falha constitutiva a separar o homem do mundo e, a ela, a linguagem seria responsável por tentar essa superação. Dessa forma, compreende-se a linguagem como fundadora da realidade do inconsciente, não há inconsciente onde não existe esse distanciamento: "há inconsciente porque há linguagem, o inconsciente é o que dizemos" (CASTRO, 1996, p. 48).

A mãe é a lei e a criança é o falo, o que configura tão somente uma ilusão subjetiva, afinal é só uma quimera narcisista que configura a falta. Mais tarde, com a castração simbólica, a criança entra no campo simbólico - agora ela tem consciência de que não significa tudo para a mãe, não é mais o seu falo, mas sim o representante deste, em uma encenação na qual ele simboliza apenas uma posição. Agora há outro em seu lugar, ocupado a partir deste momento pela Lei, a qual até mesmo a mãe deve se submeter. O falo não pertence a mais ninguém individualmente, nem ao pai, nem à mãe, nem à criança, ele é exterior a qualquer personagem. A metáfora paterna é a responsável pela Lei, ou seja, pela autoridade, é, portanto, este ser abstrato, que se encontra acima de qualquer papel social, que detém o poder, inclusive o de intercambiar a posição ocupada pelo falo.

Nesta lenda do Compadre D’Água, portanto, penso este personagem lendário como aquele que traz em si esta autoridade, reinando sobre a água, água essa que é o meio de sobrevivência desta comunidade ribeirinha.

\section{O inconsciente e as lendas}

A UNESCO, na atualidade, aconselha a utilização de uma definição mais ampla de folclore, que moldou em 1989:

\footnotetext{
"O folclore (ou a cultura tradicional e popular) é a totalidade de criações baseadas em tradições de uma comunidade cultural, expressa por um grupo de indivíduos, que são reflexos de sua identidade cultural e social. Seus padrões e valores são transmitidos verbalmente, pela imitação ou por outra maneira".
}

Suas formas são, entre outros, linguagem, literatura, música, dança, jogos, mitologia, rituais, costumes, artesanatos, arquitetura e outras artes (Neves, 2002). O folclore, assim subentendido, é tradição coletivamente preservada e verbalmente transmitida como fonte de uma identidade cultural. 


\section{Revista ComSertões}

A música, a dança e as artes cênicas são, em comunidades tradicionais, expressões vitais de uma cultura viva. Estas funções podem ser direcionadas basicamente para o entretenimento ou podem ser desenvolvidas com fins religiosos ou outros.

Segundo Neves (2002), alguns dos seus papéis podem estar manifestos para toda a comunidade, enquanto outros podem estar restritos a alguns iniciados, aos quais é permitido promulgá-los, escutá-los ou vê-los. Os mitos, as lendas, as canções e as histórias podem ser usados para transmitir tradições culturais de uma geração para a próxima. A relação entre o conhecimento tradicional e a identidade cultural de um determinado povo torna-se, então, evidente.

Mas é necessário, a princípio, esclarecer os conceitos de cultura e de identidade. Por isso é importante à referência à "cultura", como definida por Raymond Williams (1992 p. 69): "sistema significante através do qual necessariamente uma ordem social se comunica, reproduz-se, experimenta-se e se investiga".

Williams, como outros autores do século XX, usa o termo cultura como "prática social" e "produção cultural", ambos entendidos como "sistema de significações", o que ampliou o escopo de interpretação do termo, pois cultura passou a incluir toda e qualquer "prática significativa", contemplando três dimensões antes desagregadas: cultura como "modo de vida global", como "sistema de significações" e como "atividades artísticas e intelectuais". Cultura não exclui uma dessas dimensões, mas as agrega, as conjuga, pois tanto as vidas ordinárias, quanto à produção artística, literária e poética são culturais porque carregam em si significados e valores formulados no coletivo, nas interações humanas. Este sistema se encontra presente em toda forma de comunicação social.

Neste processo têm um papel fundamental as instituições, as organizações e associações, os meios de comunicação, os meios de produção e as formas culturais existentes na comunidade. Assim, a narrativa, o retrato e a representação dramática estão socialmente condicionados, em sua origem, de forma manifesta, e em seu desenvolvimento seguem radicalmente condicionados (Williams, 1992).

James Lull define que tudo o que nos rodeia é parte da cultura. O contexto de qualquer mensagem é cultural. Contribui com uma visão democrática e pluralista do conceito de cultura, o qual considera todas as culturas em um mesmo nível, numa postura de corte antropológico (Lull, 2001). Por esse motivo a cultura está relacionada à identidade. Assinala que a identificação sempre está em relação com a diferenciação das características entre 


\section{Revista ComSertões}

objetos. Esta relação entre diferença e identidade tem sido expressa também por outros autores. Lembra-nos Edgar Morin (2003), que somos a única espécie viva que sonha acordada. Nada a estranhar, uma vez que, "Shakespeareanamente" mesma matéria que os sonhos são feitos.

Assim, estabelecida a relação entre folclore, lendas, histórias e a identidade cultural de um povo, e tendo em vista o debate sobre o nascimento da identidade cultural e o papel da psique neste processo, acima reproduzido, pode-se agora compreender melhor a ligação entre as lendas e os mecanismos do Inconsciente.

\section{Processo de análise}

Os mitos, as lendas, as canções e as histórias têm o objetivo de transmitir tradições culturais de uma geração para a próxima. A relação entre o conhecimento tradicional e a identidade cultural de um determinado povo torna-se, então, evidente.

Para Raymond Williams (1992), cultura é:

(...) é todo um conjunto de práticas e expectativas, sobre a totalidade da vida: nossos sentidos e distribuição de energia, nossa percepção de nós mesmos e nosso mundo. É um sistema vivido de significados e valores - constitutivo e constituidor - que, ao serem experimentados como práticas parecem confirmar-se reciprocamente.

Esta ideia alia as visões antropológica e sociológica da cultura. Esta deixa de ser um objeto em si e se configura como um sistema de significados, entendendo a produção cultural a partir de um ponto de vista muito amplo e influenciada por um contexto social no qual se cria e se consome. O conceito de identidade é, assim, uma idéia muito próxima a de "sentido", pois como afirma a teoria semiológica de Saussure (1992), as pessoas dão sentido às coisas através da diferenciação dos signos.

Na comunidade da ilha da Canabrava, ainda não totalmente dominada pelo sistema econômico capitalista, é possível encontrar mais claramente traços das etapas infantis do

\footnotetext{
${ }^{2}$ Neologismo em alusão a William Shakespeare dramaturgo e poeta inglês, cuja obra tem valor inestimável, eterna e universal.
} 


\section{Revista ComSertões}

pensamento, como é comum ocorrer entre os povos primitivos, que na verdade se encontram na infância da Humanidade.

Vários autores se perguntaram ao longo da história o porquê da necessidade humana de fabular, de criar histórias, de fantasiar. Na narrativa, o tempo cíclico, do eterno retorno, está sempre em relação dialética com o tempo histórico, do real, do concreto. É este movimento que impulsiona a narrativa, preparando o sujeito para suas necessárias transformações, inerentes ao processo evolutivo da mente humana. É assim que o Homem avança em sua travessia, caminhante em sua jornada rumo à singularidade. Os momentos de transição estão sempre presentes nos mitos e lendas, pois eles são indispensáveis para o amadurecimento emocional do indivíduo. A humanidade caminha na direção da cultura, da civilização, do esclarecimento - uma trajetória sem retorno, no qual o tempo a impulsiona para frente, sem cessar. Ela vai de encontro às coisas novas, independente dos medos, das angústias, das resistências. Mesmo assim as culturas arcaicas, primordiais, insistem em sobreviver.

O sujeito parece ter a necessidade, no seu estágio de constituição da identidade, e no desenvolvimento desta, de transitar do Mythos para o Logos, o preço que ele paga para se tornar adulto. Mas no processo de autoconhecimento e de resgate dos sonhos, o Homem precisa percorrer o caminho inverso, do Logos para o Mythos. Sempre que desejar conhecer a si mesmo ou ao seu contexto, ele mergulha novamente nas águas da fantasia, buscando, porém, o equilíbrio entre Razão e Imaginação. Afinal, nada se perde tudo está sujeito ao eterno retorno, ao movimento cíclico. O universo mítico-mágico permanece dentro de cada um, em algum ponto de onde pode ser resgatado a qualquer momento. $\mathrm{O}$ mesmo ocorre com cada povo, com cada comunidade. Nos momentos de transição, nas etapas de transformações, nos instantes de crise, é possível resgatar a esfera mítico-lendária. A narrativa intervém assim como um processo de auto cura, como se percebe nos contos narrados por Sherazade para curar o sultão de suas feridas afetivas. Em muitas culturas, principalmente as orientais, narrar histórias é um método terapêutico de cura dos distúrbios da alma e da psique. Afinal, narrar é viver, pois o poeta detém "poderes sobrenaturais". Ele, "como o adivinho", é tomado pelas musas, num delírio divino, o enthousiasmós, no sentido etimológico, "divina habitação interior", ou "pleno de Deus". Em busca das lembranças, fontes de suas narrativas, "o poeta volta-se quase que exclusivamente para o passado" (Paiva, 2001). Pode-se também relembrar 


\section{Revista ComSertões}

que a imaginação é filha de Mnemosyne, deusa da Memória, e que, portanto, imaginar é lembrar, e lembrar é imaginar.

As fronteiras entre realidade e imaginação, fantasia e verdade, são muito tênues, é mais natural do que se pensa o ato de narrar, praticamente essencial para a sobrevivência mental e emocional do Homem, e para sua jornada de esclarecimento, ou seja, sua constituição enquanto sujeito do inconsciente. O lendário se interioriza, ganha espaço dentro do ser humano, como um reflexo do movimento interior, próximo do sonho, do devaneio, da fantasia. Ele é produto do inconsciente. Enquanto objeto de crença, a lenda nos remete a um retorno ao narcisismo, cuja pulsão sexual ainda está associada ao ego como objeto, etapa na qual o sujeito mantém a onipotência do pensamento. Isto porque, "assim como nos neuróticos obsessivos, o processo do pensamento no homem primitivo ainda é, em grande parte, sexualizado, o que supervaloriza os atos psíquicos ” (Freud, 1913, p. 12).

Os ritos desenvolvidos em torno da crença estão possivelmente relacionados ao desejo humano.Tudo que precisamos admitir é que o homem primitivo tinha uma crença imensa no poder de seus desejos, basicamente porque o que ele realiza por meios mágicos acaba se concretizando, o que lhe confere a fé em seu potencial de transformação dos desejos em realidade. De início, portanto, a ênfase é investida apenas no seu desejo. (Freud, op. Cit:1906). Através dos mecanismos de projeção e introjeção, o homem primitivo transporta as condições estruturais de sua mente para o mundo, cujos espíritos e demônios são projeção dos impulsos emocionais do homem. Este transporta suas catexias emocionais para pessoas, na direção do mundo, e com elas enfrenta seus processos mentais internos no âmbito externo (Freud, op. Cit.).

Para falar de um censor social, o superego, Freud (1927) criou um mito próprio, no qual o pai é assassinado pelos filhos, que desejavam a posse das mulheres da tribo. A partir daí, ele postula a ideia de que mediante o processo de introjeção, a imagem paterna é fixada e identificada no ego, infligindo ao indivíduo as mesmas penas que o mesmo tentava aplicar ao pai. Para Freud, o mecanismo de introjeção - identificação do ego - às vezes falha, e então persiste na idade adulta uma atitude de hostilidade, em especial contra os representantes da autoridade. $\mathrm{O}$ suposto delito social contido representa um parricídio simbólico, isto é, uma vingança contra a tirania primitiva e opressora do genitor. A partir da culpa instaurada, a intenção equivale ao ato. A outra parte da agressividade é projetada para fora do indivíduo, extravasando a tendência afetiva direcionada para outras fontes. Desse modo o sujeito se vê 


\section{Revista ComSertões}

livre da responsabilidade de seus atos e desaparece o conflito entre desejo e dever. Se num primeiro momento o sujeito é barrado pela função da linguagem, em uma segunda etapa ele é barrado pela lei do pai (Freud, 1929/1930).

\section{Considerações finais}

O Compadre mora no rio e tem livre arbítrio entre a terra e a água, bem como a posse do rio. Ele é poderoso, e em torno dele as pessoas vão construindo suas vidas. Assim pode-se dizer que o Compadre D’Água é a projeção, a representação do grande pai, pois exerce a função de autoridade máxima, que proíbe e barra qualquer infração, mas que também permite concessões. O Compadre desenvolve com as pessoas uma relação ambivalente, tanto pode ser amigo como inimigo, comportamentos que se alternam. Enquanto inimigo, não garante a pesca. Para ser amigo, ele apenas espera que lhe ofereçam fumo e cachaça. A partir da briga pela posse do rio, de onde provém a subsistência, personifica uma privação que é real e uma falta que é simbólica, evocando a representação da figura paterna. Assim como essas características são encontradas durante o desenvolvimento infantil do sujeito frente ao falo materno, elas também estão presentes na relação do sujeito com a lenda.

A crença no lendário, a partir da onipotência do pensamento e da valorização dos atos psíquicos, permite às pessoas construírem suas relações de vida em torno do Compadre D’Água, articulando desejo e existência humana, mediante a lei do falo, a lei do pai. A função da lei, representada pelo Compadre quando este é inserido no contexto cultural, institui a ordem humana. Ela representa uma condição estabelecida anteriormente, a qual regula a troca entre os homens, e assim pode, na experiência concreta, combinar de maneira diferente e complementar o indivíduo e o objeto. Este processo permite que as mulheres engravidem do Compadre D’Água, e também que os pescadores conversem com ele, assim como permite, ainda, a existência de um Compadre há quinze anos.

Numa analogia, pode-se dizer que a crença no Compadre D’Água nada mais é do que a manifestação do estágio primitivo do desenvolvimento, cuja eficácia reside no outro como portador do lendário e não naquele que exerce sua função. Concluindo, pode-se dizer que, dessa forma, a lenda encerra em si mesma seu objetivo, ou seja, atua como um organizador social mediante a proibição do desejo incestuoso, representado pelo Compadre D’Água. 
Revista ComSertões

\section{REFERÊNCIAS}

CASCUDO, Luís Câmara. Dicionário do Folclore Brasileiro. $10^{\mathrm{a}}$ ed. Rio de Janeiro: Ediouro, 1972.

CASTRO, Eliane de Moura. Psicanálise e Linguagem. São Paulo: Ática, 1996.

FREUD, Sigmund. O Ego e o Id (1923). v.19. Rio de Janeiro: Imago, 1980. (Edição Standard Brasileira da Obras Psicológicas Completa de Sigmund Freud, 24 volumes).

Sobre o Narcisismo (1914). v. 14. Rio de Janeiro: Imago, 1980. (Edição Standard Brasileira da Obras Psicológicas Completa de Sigmund Freud, 24 volumes).

A Dissolução do Complexo de Édipo (1927). V. 19. Rio de Janeiro: Imago, 1980. (Edição Standard Brasileira da Obras Psicológicas Completa de Sigmund Freud, 24 volumes).

LACAN, Jacques. O Estádio do Espelho como Formador da Função do eu. In: ESCRITOS. Rio de Janeiro: Jorge Zahar, 1998.

Função e Campo da Fala e da Linguagem em Psicanálise. In: ESCRITOS. Rio de Janeiro: Jorge Zahar, 1998.

LULL, James. Comunicação em um mundo de crise. Austrália, Blackwell, 2002.

MORIN, Edgar. Os sete saberes necessários á educação do futuro. Rio de Janeiro, Cortez, 2003.

NEVES, Maria Helena de Moura. A Gramática: História, teoria e análise, ensino. São Paulo, UNESP, 2002.

PAIVA, J. M. Os Tempos Impossíveis: Perigo e Palavra no Sertão. Rio de Janeiro, Imagem Virtual, 2001.

PIERSON, D. O Homem no Vale do São Francisco. Tomo I, II e II. Rio de Janeiro, Zahar editora, 1972.

SAUSSURE, F. Curso de Linguística. São Paulo. Cultrix, 1992.

WILLIANS, Raymond. Cultura e Sociedade. Rio de Janeiro, Paz e Terra, 1992. 